\title{
Avaliação de vidro reciclado granulado como meio filtrante de herbicidas em meio aquoso
}

\author{
Odilio B. G. Assis ${ }^{1} \&$ Delia do C. Vieira
}

\begin{abstract}
RESUMO
Neste trabalho resultados e considerações sobre o uso de vidro reciclado na forma de material granulado, como potencial meio filtrante para remoção de agrotóxicos diluídos em água são apresentados. Para esta avaliação garrafas e vasiIhames de vidro transparente foram fragmentados e moídos até partículas com tamanhos inferiores a $1 \mathrm{~mm}$ e ensaios de filtração gravitacional realizados em colunas, em escala laboratorial. O herbicida atrazina foi escolhido como contaminante em virtude de ser um composto altamente tóxico e amplamente empregado no Brasil. Análises por cromatografia gasosa indicam a retenção de agrotóxicos pelo meio poroso, em todo o intervalo de concentrações avaliadas $(0,5 ; 1,0$; 3,0; 10 e $\left.15 \mathrm{mg} \mathrm{L}^{-1}\right)$. O vidro apresentou-se como material de fácil manuseio e potencialmente atraente para uso como meio coadjuvante em filtragem lenta.
\end{abstract}

Palavras-chave: filtração, meio poroso, atrazina, remediação ambiental

\section{Evaluation of crushed recycled glass as a filtration medium of agrotoxic materials in aqueous media}

\begin{abstract}
In this paper results and consideration about the use of recycled glass, as a granulated medium for filtration interaction with diluted agrotoxic materials in water, are presented. For this purpose, transparent bottles and glass containers were first fragmented and than crushed into pieces with sizes $<1 \mathrm{~mm}$. Gravitational filtration tests were carried out in columns, in laboratorial scale. The herbicide atrazine was chosen as a standard contaminant due to its high toxicity and intensive use in Brazil. The results, from gas chromatography analysis, showed that the contamination was retained by the porous medium over all ranges of concentration $\left(0.5,1.0,3.0,10\right.$ and $\left.15 \mathrm{mg} \mathrm{L}^{-1}\right)$, which was dependent on the initial contamination degree. With regard to glass as a raw material, it showed itself to be a quite amenable material, potentially attractive for uses as a coadjutant medium in slow filtration.
\end{abstract}

Key words: filtration, porous medium, atrazine, environmental remediation 


\section{INTRODUÇÃO}

Os agrotóxicos são determinantes para a boa produtividade na atividade agrícola, seja para o controle de pragas, doenças, plantas daninhas ou para regular os processos fisiológicos das plantas; seu uso, contudo, tem sido muitas vezes, irracionalmente empregado na lavoura, em proporções comumente superiores às ideais, causando impactos e danos ambientais de difícil remediação. Um dos principais males do uso incorreto desses insumos é, sem dúvida, a contaminação do meio ambiente com sérias implicações à saúde humana. Segundo Ueta et al., (1999), calcula-se que só cerca de $0,1 \%$ dos agroquímicos atinja o alvo específico enquanto os restantes $99,9 \%$ da aplicação têm potencial para se mover em diferentes compartimentos ambientais, tais como solo e águas subterrâneas. Os chamados POPs (Poluentes Orgânicos Persistentes, Persistent organic pollutants), consistem na classe de agrotóxicos que, por não se ligarem às partículas de solo, apresentam a maior probabilidade de contaminação. Vários POPs, notadamente alguns agrotóxicos organoclorados, como o DDT e o HCH, têm sido completamente banidos do uso agrícola na maioria dos países desenvolvidos (Lisboa, 2002). Embora o Brasil figure entre os três maiores consumidores mundiais de defensivos agrícolas, só recentemente definiu uma legislação específica sobre o uso racional dos organoclorados (Cruz, 2007).

Uma das piores conseqüências do uso excessivo de agrotóxicos decorre da lavoura irrigada cujas águas, contendo os resíduos químicos diluídos, infiltram com facilidade no solo atingindo lençóis que correm para mananciais superficiais, contaminando águas muitas vezes destinadas ao uso animal e humano (Tomita \& Beyruth, 2002).

A remoção de agrotóxicos do meio aquoso não consiste em processos triviais. As moléculas são diminutas e se associam facilmente à água, o que não permite uma remoção por filtração lenta (Coelho, 2003). Sistemas mais eficazes, como os de osmose reversa, filtros CAG adsorvedores ou dispositivos de biofiltragem, são consideravelmente mais dispendiosos e complexos inviabilizando o uso em larga escala; neste sentido, o desenvolvimento de metodologias alternativas, de baixo custo, ainda que com eficiências inferiores tornase, sem dúvida, de interesse e potencialmente estratégicas como recurso coadjuvante.

Recentemente, vidros fragmentados, como o PGA (pulverized glass aggregate), têm sido satisfatoriamente avaliados em sistemas de purificação em larga escala, como em leito de filtração lenta, como uso alternativo à areia (Piccirillo \& Letterman, 1997; Rutledge \& Gagnon, 2002). O vidro, além de ser $20 \%$ mais leve que a areia, apresenta melhor empacotamento em função do formato angular de suas partículas, o que gera uma retenção mais eficiente sem perdas na permeabilidade (CWC Publication, 1997).

Uma característica fundamental dos materiais vítreos é que eles podem sofrer alterações das propriedades físico-químicas superficiais, como a modificação ou implante de grupos funcionais, que alteram a hidrofilicidade ou mesmo promovam mudanças para um comportamento hidrofóbico, o que é conseguido por tratamentos químicos relativamente sim- ples (Chartier, 1997). Esses tratamentos intensificam as interações com compostos orgânicos, tornando o vidro definitivamente um material de interesse para a confecção de dispositivos de adsorção e retenção superficial, como membranas ou meios ativos para uso em microfiltração.

A este cenário se soma que cerca de 7,5\% em peso do total de lixo doméstico gerado no mundo correspondem a vidros descartados (garrafas, vasilhames diversos, vidros planos da construção civil etc.) Para se ter uma idéia numérica dessa quantidade, os EUA consomem, em média, um volume de embalagens de vidro superior a $30 \mathrm{~kg} \mathrm{hab}^{-1} \mathrm{ano}^{-1}$ (Malisch et al., 1975) e no Brasil esses valores são estimados em algo como $6 \mathrm{~kg}$ per capita por ano (Rodrigues \& Peitl, 1999) o que, de forma geral, traduz em milhares de toneladas de resíduos vítreos diariamente rejeitados e acumulados como lixo, ou seja, consiste de um material abundante e praticamente gratuito.

A unidade da Embrapa Instrumentação Agropecuária em São Carlos, SP, já há algum tempo, tem avaliado potenciais usos para o vidro reciclado, sobretudo na confecção de dispositivos de pequeno porte para filtração de água, de baixo custo e de fácil confecção, para uso geral e em particular na zona rural (Divino et al., 1998; Assis et al., 2001; Assis, 2006). O propósito do presente estudo é avaliar pós de vidro, produzidos a partir de material reciclado, como meio alternativo de interação e filtração de herbicida diluído em água potável.

\section{MATERIAL E MÉTODOS}

\section{Produção dos pós de vidro}

A matéria prima constituiu-se de garrafas transparentes, de mesma origem, cuja composição química média, expressa em massa, é: $\mathrm{SiO}_{2}$ (72,8\%); $\mathrm{Na}_{2} \mathrm{O}$ (13,2\%); $\mathrm{CaO}(11,2 \%)$; $\mathrm{MgO}(0,16 \%) ; \mathrm{Al}_{2} \mathrm{O}_{3}$ (2,13\%); $\mathrm{FeO} / \mathrm{Fe}_{2} \mathrm{O}_{3}$ (0,039\%); $\mathrm{K}_{2} \mathrm{O}$ (0,09\%), segundo determinação da Saint-Gobain (Centro Técnico de Elaboração do Vidro). As garrafas foram previamente lavadas, secadas em estufa e manualmente fragmentadas em partículas da ordem de $1,5 \mathrm{~cm}$; este material foi, em seguida, reduzido a pó em moinho de bolas de alumina, em rotação de 36 RPM por 1 h. A morfologia e a dimensão aproximada dos grãos foram avaliadas por microscopia eletrônica de varredura (Philips XL 30).

As superfícies vítreas sofreram tratamento químico com o objetivo de limpar e elevar reatividade da superfície. Seguiu-se a seqüência proposta por Kern (1993), conhecida como técnica "piranha”, que consiste na imersão dos pós em uma solução de $\mathrm{H}_{2} \mathrm{SO}_{4} / \mathrm{H}_{2} \mathrm{O}_{2}(7: 3 \mathrm{v} / \mathrm{v})$. O sistema é então aquecido até início de fervura e depois de resfriado conduzido para limpeza no ultra-som, durante $40 \mathrm{~min}$; após este período o material é exaustivamente lavado com água pura, seguido de imersão em solução de $\mathrm{H}_{2} \mathrm{O} / \mathrm{NH}_{4} \mathrm{OH} / \mathrm{H}_{2} \mathrm{O}_{2}$ (5:1:1 v/v/v) e novamente limpos com água.

\section{Ensaios de filtragem e análise}

Os ensaios de adsorção foram realizados por filtragem gravitacional de soluções aquosas contaminadas por 
passagem em colunas com o material fragmentado. Elegeu-se o agrotóxico atrazina como contaminante padrão, já que se trata de um herbicida amplamente empregado no Brasil, no controle geral de ervas daninhas, em particular na plantação de cana-de-açúcar e milho, sendo um composto de alta mobilidade e persistência, danoso à saúde humana e facilmente lixiviado para a água.

Frações próximas a $70 \mathrm{~g}$ de vidro moído foram acondicionadas em colunas de 1 polegada de diâmetro interno. Séries de quatro colunas foram preparadas para cada ensaio objetivando-se a coleta de dados estatísticos. Soluções aquosas de atrazina, a partir de produto de origem comercial (Ciba-Geyg, com o nome fantasia Gesaprim 500), foram preparadas nas concentrações de 0,$5 ; 1,0 ; 3,0 ; 10$ e $15 \mathrm{mg} \mathrm{L}^{-1}$ a partir de solução estoque, em pH próximo a 3,5;

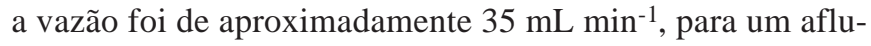
ente total de $300 \mathrm{~mL}$.

A quantificação da atrazina, tanto inicial quanto após a passagem pelas colunas, foi estabelecida por cromatografia gasosa pela extração em fase sólida (cartuchos C-18 previamente ativados com acetato de etila); as análises por cromatografia foram realizadas nas seguintes condições: i) detector fósforo/nitrogênio; ii) coluna capilar de metil-siloxano; iii) injetor e detector operados a $300^{\circ} \mathrm{C}$; iv) coluna com programação de temperatura: inicialmente a $100^{\circ} \mathrm{C}$ por 2 min, seguido de aquecimento até $300^{\circ} \mathrm{C}$ com uma taxa de aquecimento de $10{ }^{\circ} \mathrm{C} \mathrm{min}^{-1}$, permanecendo $10 \mathrm{~min}$ nessas condições; v) volume injetado de $2 \mathrm{~mL}$ e vi) gás de arraste: hidrogênio sob um fluxo 1,0 $\mathrm{mL} \mathrm{min}^{-1}$ Empregouse equipamento Hewlwtt Packard 5890, série II.

As concentrações das amostras foram estabelecidas a partir da curva de calibração ajustada à equação: 5,812 x 10-5 $\mathrm{x}$ [Ap] com um coeficiente de correlação $\mathrm{r}=0,9985$ e a percentagem removida estabelecida pela diferença entre a concentração da solução controle $\left(\mathrm{Ap}_{0}\right)$ e a concentração da solução após a filtragem $\left(\mathrm{Ap}_{\mathrm{f}}\right)$.

\section{RESULTADOS E DISCUSSÃO}

A Figura 1 apresenta o aspecto dos pós, em amostra moída, sob microscopia eletrônica de varredura, sendo possível visualizar a distribuição de formatos e tamanhos gerados no período de moagem. De modo geral, os pós de vidro fragmentados e moídos não seguem um padrão definido de formato e apresentam dimensões variadas e em média inferiores a $100 \mathrm{~mm}$, ou seja, se constituem de partículas consideravelmente finas. Embora segundo Driscoll (1986), para a formação adequada de um leito é desejável certo grau de uniformidade das partículas para que seja minimizada a segregação de material durante o fluxo sob pressão, variações de formatos, por sua vez, garantem um empacotamento mais denso, configurando um meio com maior área de interação. Tipicamente, partículas em formatos regulares e mais arredondadas configuram um meio com porosidade mais uniforme porém com menor tortuosidade que as observadas para empacotamento com materiais com características angulares (Thovert et al., 1993). Um percurso maior do fluido durante o processo de filtração pode elevar a capacidade de retenção, sobretudo quando o principal mecanismo de remoção se dá por interações superficiais (Assis \& Claro, 1999).

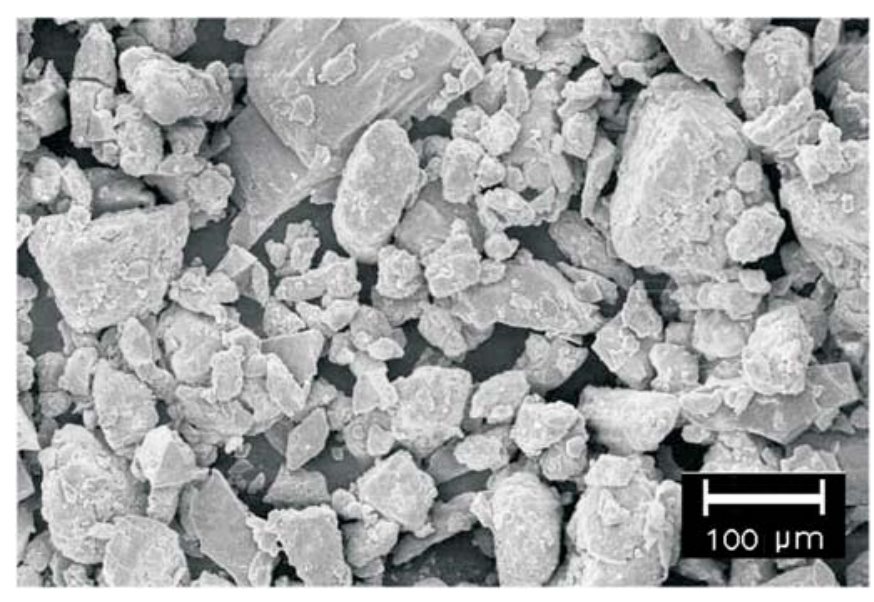

Figura 1. Aspecto do pó de vidro obtido após $2 \mathrm{~h}$ de moagem

A Figura 2 ilustra um cromatograma típico referente à atrazina em solução, na concentração de $1 \mathrm{mg} \mathrm{L}^{-1}$ de herbicida, com um único sinal em 13,56 min, correspondendo ao tempo de retenção da amostra no sistema e tomado como padrão para as análises. Na Figura 3 estão organizados os resultados de retenção medidos.

De modo geral, há boa reprodutibilidade entre as diversas colunas experimentadas indicando que, quanto maior a contaminação inicial menor é a proporção relativa de agrotóxico retido o que, de certa forma, é evidente, pois há saturação da capacidade de adsorção superficial, que é o principal mecanismo de filtragem neste caso, sendo que o volume de material particulado foi o mesmo para todas as colunas.

A atrazina (6-cloro-N-etil-N'-(1-metiletil)-1,3,5-triazina2,4 diamina), de fórmula química $\mathrm{C}_{8} \mathrm{H}_{14} \mathrm{ClN}_{5}$, pertencente à família das s-triazinas (estrutura de anel simétrica), é caracterizada por um aromático heterocíclico clorado e N-alquilado, compostos receptores de prótons e se tornam carregados

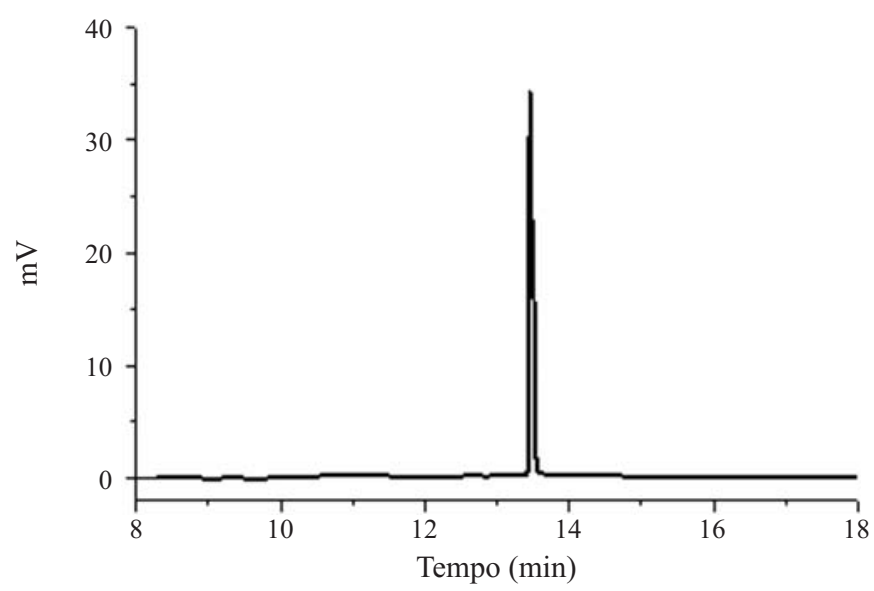

Figura 2. Cromatograma padrão obtido para a atrazina em solução 


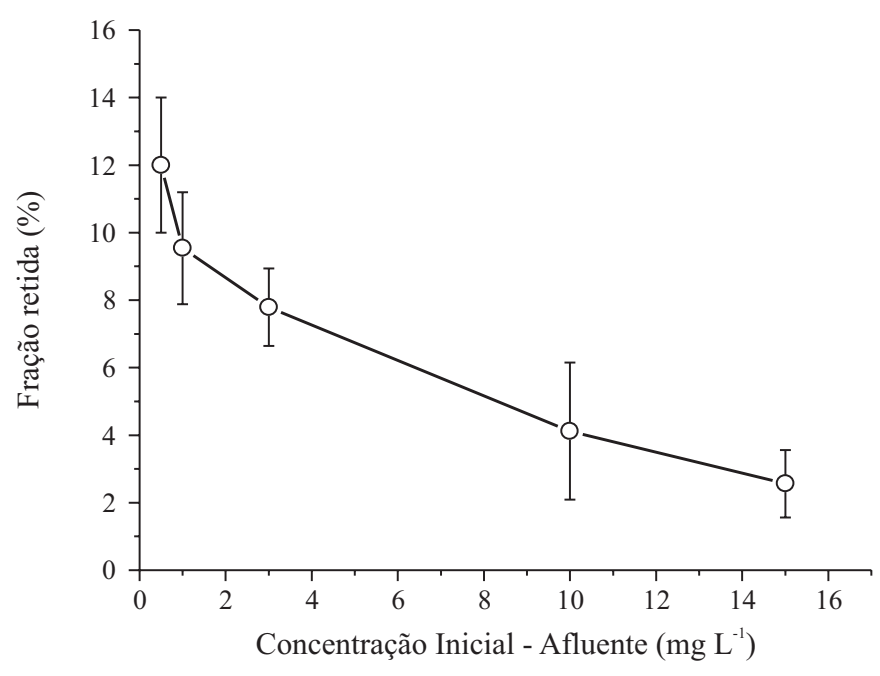

Figura 3. Frações retidas de herbicida em função da concentração inicial por filtração em coluna com material vítreo granulado

positivamente quando colocados em meio aquoso (Ahlrichs et al., 1974; Khan, 1980), principalmente próximo do seu pKa (1,70). Segundo Dombek et al. (2001), dependendo da pureza do herbicida, de 5 a $30 \%$ das moléculas de atrazina podem estar no estado protonado em pHs entre 2 e 3, ou seja, há forte possibilidade de ocorrência de interação com os demais compostos ionizados ou grupos superficiais devido à presença de cargas; entretanto, interações hidrofóbicas, assim como as ligações de hidrogênio e formação de complexos, evidentemente devem ser consideradas; a superfície do vidro é composta de ligações siloxanas (Si-O-Si) e sobretudo por grupos silanóis ( $\mathrm{SiOH})$; os grupos silanóis se distribuem aleatoriamente na superfície e são por demais polares, embora na presença de água se possam dissociar gerando estruturas com cargas superficiais, segundo uma reação simples do tipo (Sinton \& Lacourse, 2001):

$$
(\text { Si-O-R })_{\text {vidro }}+\mathrm{H}_{2} \mathrm{O} \rightarrow(\mathrm{Si}-\mathrm{O}-\mathrm{H})_{\text {vidro }}+\mathrm{R}^{+}+\mathrm{OH}_{\text {solução }}^{-}
$$

Em razão de sua inespecificidade, os radicais hidroxilas $(\mathrm{OH})$, presentes nos grupos silanóis, reagem com grande variedade de compostos, majoritariamente com compostos orgânicos presentes em meio aquoso (Czaplicka, 2006). De acordo com Cheney et al. (1998), ao avaliarem a adsorção de atrazina dissolvida sobre superfícies de óxido de manganês $\left(\mathrm{MnO}_{2}\right)$, que possui estrutura similar ao vidro $\left(\mathrm{SiO}_{2}\right)$, os autores concluíram que as moléculas de atrazina apresentam forte tendência de transferência de prótons com o nitrogênio do anel na posição três e com os grupos aminos; portanto, esses grupos podem unir o herbicida à superfície ácida dos óxidos metálicos, facilitando a transferência de cargas. Em uma primeira etapa da reação dáse a oxidação parcial da atrazina por troca de elétrons com os sítios na superfície reativa do óxido. Resultados similares foram observados para a interação da atrazina com óxidos presentes no solo (Kovaios et al., 2006). Ringwald \& Pemberton (2000), realizaram um estudo sobre a adsorção de compostos aromáticos e heteroaromáticos com a superfície da sílica $\left(\mathrm{SiO}_{2}\right)$ hidratada e desidratada concluindo que interações do tipo ligação de hidrogênio predominam na adsorção de compostos aromáticos devido à protonação do nitrogênio $(\mathrm{N})$ do anel, que resulta em espécies tipo ácido de Bronste, ou seja, os resultados indicam que os grupos silanóis da superfície vítrea são os sítios responsáveis pela adsorção desses compostos, podendo-se propor um modelo, como o apresentado na Figura 4.
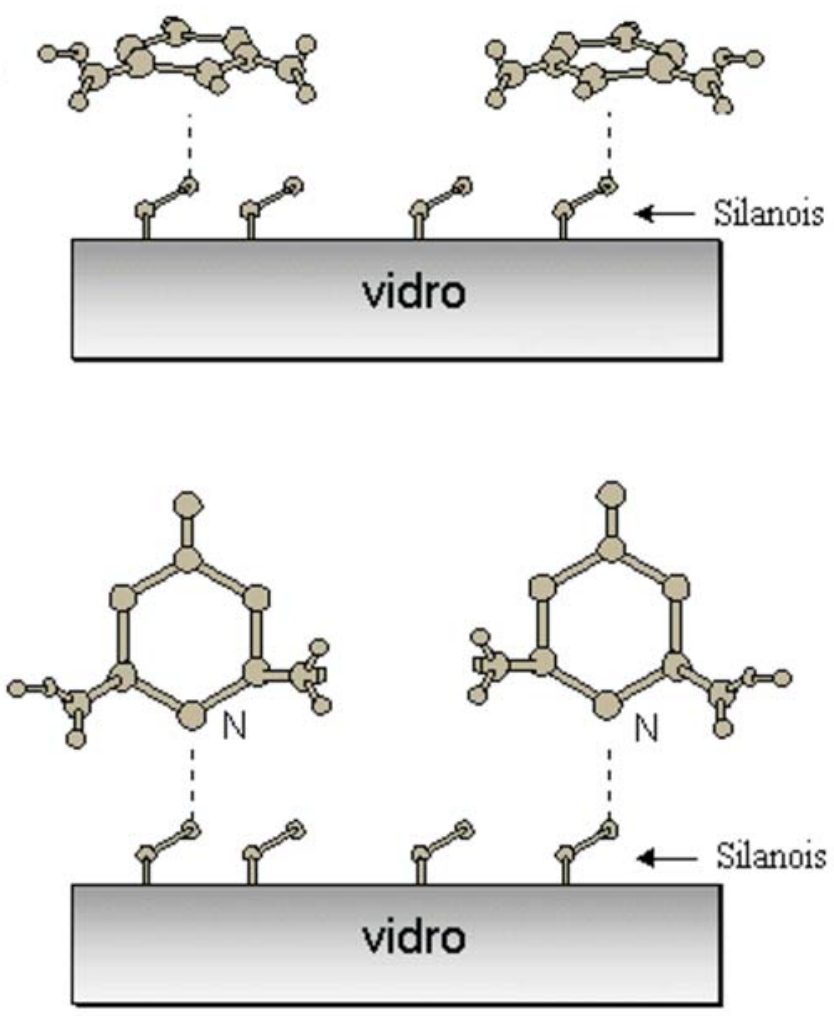

Figura 4. Representação esquemática da retenção do herbicida atrazina sobre superfícies vítreas, tendo por base as considerações de Ringwald \& Pemberton (2000)

Para ser eficiente, em processo de filtragem requer a ação conjunta de diversos mecanismos, principalmente o de oferecer uma barreira física a patógenos e impurezas dimensionais; neste aspecto e embora não avaliado neste estudo, um leito de vidro granulado deve apresentar certa eficiência devido à natureza angular de suas partículas; neste sentido, os grãos de vidro apresentam maior área de filtragem, fato que pode ser explorado como capacidade de retenção, o que pode ser superior aos silicatos arenosos convencionais. Outro aspecto interessante no vidro é a possível redução do "biofouling”, isto é, do entupimento gerado pelo acúmulo de material biológico retido na superfície do meio. Avaliações realizadas pela Dryden Aqua na Grã-Bretanha, mostram que vidro particulado reduz significativamente o problema de biofouling em leitos de filtração rápida em grande intervalo de pressões (Dryden Aqua Ltd., 2004).

O que deve ser observado com certo critério, é o fato de que o vidro tem densidade menor que a areia o que pode, em movimentos circulatórios intensos, gerar movimentação e reacomodação, alterando as características originais do 
leito; granulado de vidro, contudo, pode ser facilmente processado e classificado em diversas dimensões satisfazendo diversas aplicações em filtragens.

\section{CONCLUSÕES}

1. De modo geral se vê, em função das características examinadas, que a aplicação de vidro moído pode vir a ser promissora não apenas do ponto de vista econômico mas também como meio coadjuvante de filtragem, sobretudo na remediação de água industriais.

2. Avanços podem ser conseguidos alterando o tamanho de partículas (maior área superficial para interação), o que pode elevar a eficiência do processo.

3. O uso de pós de vidro reciclado pode ser particularmente interessante na remoção de contaminantes em baixas concentrações, conforme resultados obtidos.

\section{AgRADECIMENTOS}

Os autores são gratos à FAPESP e à EMBRAPA, pelos recursos disponibilizados.

\section{LITERATURA CITADA}

Ahlrichs, J. L. Pesticides in soil and water. Inc., 2. ed, Madison: Soil Science Society of America Publischer, 1974. p.562.

Assis, O. B. G. O uso de vidro reciclado na confecção de membranas. Cerâmica, v.52, n.321, p.105-113, 2006.

Assis, O. B. G.; Claro, L. C. Processing of soda lime glass membranes by filler principle for the enzyme coupling application. Journal of Non-Crystalline Solids, v.247, p.237-240, 1999.

Assis, O. B. G.; Ferrante, M.; Vieira, D. C. Open pore microfiltration membranes produced from waste glass. Glass Technology, v.42, n.3, p.101-103, 2001.

Chartier, P. La surface du verre: bases scientifiques pour la recherche industrielle. Verre, v.3, n.3, p.5-13, 1997.

Cheney, M. A.; Shin, J. Y.; Crowley, D. E.; Alvey, S.; Malengreau, N.; Sposito, G. Atrazine dealkylation on a manganese oxide surface. Colloids and Surfaces A, v.137, p.267-273, 1998.

Coelho, E. R. C. Avaliação da filtração lenta em leitos de areia e carvão ativado granular na remoção de atrazina. In: Seminário Estadual sobre Saneamento e Meio Ambiente, 5, 2003, Anais...Vitória: ABES, 2003. 8p.

Cruz, M. DDT está proibido no Brasil. Agência Amazônia. www.agenciaamazonia.com.br/ index.php?option=com_content \&task=view\&id=1174\&Itemid=29, 02 Jul 2007.

CWC Publication. Evaluation of crushed recycled glass as a filtration medium in slow rate filtration. Technology Brief \# GL95-4, Washington: Division of the Pacific NorthWest Economic Region, 1997. 2p.
Czaplicka, M. Photo-degradation of chlorophenols in the aqueous solution. Journal of Hazardous Materials, v.134, n.1-3, p.45-59, 2006.

Divino, G.; Assis, O. B. G.; Vieira, D. C. Desenvolvimento de filtros de baixo custo de interesse à agroindústria. In: Simpósio Nacional de Instrumentação Agropecuária, 2, 1998, Anais... São Carlos: EMBRAPA, 1998. p.328-334.

Dombek, T.; Dolan, E.; Schultz, J.; Klarup, D. Rapid reductive dechlorination of atrazine by zero-valent iron under acidic condition. Environmental Pollution, v.111, p.21-27, 2001.

Driscoll, F. G. Groundwater and wells. Inc., St. Paul: Johnson Filtration Systems, 1986. 1089p.

Dryden Aqua Ltd. Project to examine the use of recycled glass as filtration media in the treatment of drinking water and wastewater. Edinburgh: R\&D Report: Glass, The Waste \& Resources Action Programme, 2004, 14p.

Kern, W. Handbook of semiconductor wafer cleaning technology. New Jersey: Noyes Publications, Cap.1, 1993, p.19.

Khan, S. U. Pesticides in the environment. 2.ed., Amsterdam: Elsevier Scientific Publishing Company, 1980. p.240.

Kovaios, I. D.; Paraskeva, C. A.; Koutsoukos, P. G.; Payatakes, A. C. Adsorption of atrazine on soils: model study. Journal of Colloid and Interface Science, v.299, n.1, p.88-94, 2006.

Lisboa, M. A. Convenção dos poluentes orgânicos persistentes. Série Cadernos do CEJ, v.21, p.153-166, 2002.

Malisch, W. R.; Day, D. E.; Wixson, B. G. Use of domestic waste glass for urban paving. Washington: National Environmental Research Center, U.S. Environmental Protection Agency, Summary Report EPA-670/2-75-053, 1975, 18p.

Piccirillo, J. B.; Letterman R. D. Examination of pulverized waste recycled glass as filter media in slow sand filtration. Albany: National Technical Information Service, NYSERDA Report No. 97-13, Reference n. PB98-158959, 1997, 144p.

Ringwald, S. C.; Pemberton, J. E. Adsorption interactions of aromatics and heteroaromatics with hydrated and dehydrated silica surfaces by Raman and FTIR spectroscopies, Environmental Science \& Technology, v.34, n.2, p.259-265, 2000.

Rodrigues, A. C. M.; Peitl, O. Reciclagem de vidros no Brasil: Um panorama geral. In: El reciclado del vidrio em Iberoamérica. Madrid: CYTED, 1999, p.33-46.

Rutledge, S. O.; Gagnon, G. A. Comparing crushed recycled glass to silica sand for dual media filtration. Journal of Environmental Engineering and Science, v.1, p.349-358, 2002.

Sinton, C. W.; Lacourse, W. C. Experimental survey of the chemical durability of commercial soda-lime-silicate glasses. Materials Research Bulletin, v.36, p.2471-2479, 2001.

Thovert, J. F.; Salles, J.; Adler, P. M. Computerized characterization of geometry of real porous media: their discretization, analysis and interpretation. Journal of Microscopy, v. 170, p.65-79, 1993.

Tomita, R. Y.; Beyruth, Z. Toxicologia de agrotóxicos em ambiente aquático. O Biologico, v.64, n.2, p.135-142, 2002.

Ueta, J.; Pereira, N. L.; Shuama, I. K.; Cerdeira, A. L. Biodegradação de herbicidas e biorremediação: Microoganismos degradores do herbicida atrazina. Biotecnologia: Ciência e Desenvolvimento, v.2, n.10, p.10-13, 1999. 